\title{
Trends in Life Expectancy by Level of Education and Occupational Social Class in Finland 1981-2000
}

\author{
TAPANI VALKONEN, Ph.D., Professor \\ Department of Sociology, Population Research Unit, University of Helsinki \\ PEKKA MARTIKAINEN, Ph.D., Senior Researcher \\ Helsinki Collegium for Advanced Studies, University of Helsinki
}

\section{Abstract}

The study analyses trends in life expectancy by level of education and by occupational social class in Finland from 1981 to 2000 to assess to what extent these trends have been in accordance with the target of reducing socioeconomic differences in life expectancy set in the Government public health programme. The study is based on the census records for the population aged 35 or over, which have been linked to the death records for the years 1981 to 2000. The results show that, contrary to the public health target, the difference in the life expectancy between persons with tertiary and basic education and that between upper non-manual and manual occupational classes increased during the 1990s. Differences in the trends in mortality from alcohol-related causes of death and from other cancers than lung cancer accounted for most the increase in the socioeconomic gap among men. Different from the 1980s changes in cardiovascular mortality did not contribute to the increase in the socioeconomic gap. Among women the increase in the socioeconomic gap was mainly due to the heterogeneous group of 'other diseases' and cancers other than lung and breast cancer.

Keywords: Life expectancy, education, occupational social class, public health, mortality, Finland

\section{Introduction}

Reducing of socioeconomic inequalities in morbidity and mortality has been adopted as an important goal of government health policies in many countries (Mackenbach and Bakker 2002). An impetus for this has been the document 'Health for All by the Year $2000^{\prime}$ agreed upon by the European member states of the World Health Organization in 1984 according to which 'by the year 2000 the actual differences in health status between population groups ... should be reduced by at least 25 percent' $^{\prime}$ (WHO 1985). 
Studies monitoring trends in socioeconomic differences or inequalities in mortality have been mostly based on information on absolute or relative differences in age-adjusted death rates by occupation-based social class or level of education (e.g. Valkonen et al. 2000; Mackenbach et al. 2003; Kunst et al. 2004; Rognerud and Zahl 2006). Differences in death rates are, however, somewhat problematic from the point of view of monitoring trends in inequalities in mortality. The results are often difficult to understand for policy makers and lay audiences particularly in situations, where the results on relative differences lead to different conclusions than those on absolute differences (Valkonen 1999). Most studies have covered only limited age-ranges such as persons aged 35 to 59 and excluded the older age groups in which most deaths occur.

The World Health Organization (1999) gave a new and more specific formulation for the socioeconomic equality target stating it in terms of life expectancies: by the year 2020 'the gap in life expectancy between socioeconomic groups should be reduced by at least 25 per cent' (Target 2.1). As far as we know only the government of Finland has followed the WHO renewed way of setting targets for reducing socioeconomic differences in terms of life expectancy. According to one of the targets set in the Government Health 2015 Public health programme (Government resolution 2001) the difference in life expectancy at age 35 between persons with tertiary education and basic education should diminish by at least 20 percent from 1991-95 to 2015. A parallel target was set for the reduction of the difference in the life expectancy between upper-level non-manual workers and manual workers.

Studies on trends in socioeconomic differences in life expectancy have not been common. For countries other than Finland we are aware only of results on life expectancy by occupation-based social class for England and Wales (Hattersley 1999; Donkin et al. 2002) and Sweden (Burström, Johannesson, Diderichsen 2005) and by level education for Estonia (Leinsalu, Vågerö, Kunst 2003) and the United States (Crimmins et al. 2001). Trends in life expectancy by occupational class in Finland have been analysed in several studies (e.g. Valkonen et al. 1993; Martikainen, Martelin, Valkonen 2001; Valkonen, Ahonen, Martikainen 2003). Life tables by level of education have been published for the years 1981-93 (Valkonen et al. 1993; Martikainen and Valkonen 1995), but not analysed further.

The first aim of this study is to describe trends in life expectancy by level of education and by occupational class in Finland from 1981 to 2000 and to assess to what extent the trends have been in accordance with the targets set in the Public Health Programme. Secondly, we will analyse the causes for the changes during the 1990s. This is done by decomposing the changes in life expectancy in the educational categories and occupational classes by age and cause of death. A third purpose of the study is also to assess to what extent the results are similar or different when two 
different indicators for socioeconomic position, level of education and occupational class, are used.

\section{Data and methods}

We use data from the longitudinal census register of Statistics Finland covering the censuses in 1980, 1985, 1990 and 1995. The census records have been linked to the death records for the years 1981 to 2000 by means of person numbers. The linked data set covers all persons who lived in Finland in the census years mentioned above and all deaths among them during the period 1981-2000. The linkage of the death records was almost complete, and the share of deaths not linked was less than 0.5 per cent.

The analysis is restricted to persons aged 35 years and over, because the socioeconomic position of younger persons may not be stable. For reasons of data protection the data were obtained from Statistics Finland in tabulated form. Person years and deaths by cause were tabulated by year, sex, five-year age group, level of education and occupational class.

Three education categories were based on information on the highest registered degree or certificate: basic education (less than 10 years or education unknown), secondary education (10-12 years), and tertiary education (13 or more years). During the time covered by the study the distribution of education changed considerably. In 198171 percent of the study population had basic education only, but in 2000 this share was 45 percent (Table 1).

Table 1. Distribution of population aged 35 and over by level of education and by occupational class, men and women in Finland in 1981 and 2000.

\begin{tabular}{lrrrr}
\hline & & MEN & & \multicolumn{2}{c}{ WOMEN } \\
& 1981 & 2000 & 1981 & 2000 \\
\hline Level of education & & & & \\
Basic & 68.8 & 42.7 & 73.8 & 46.2 \\
Secondary & 22.4 & 42.8 & 19.8 & 40.2 \\
Tertiary & 8.8 & 14.5 & 6.4 & 13.6 \\
All & 100 & 100 & 100 & 100 \\
\hline Occupational class & & & & \\
Upper non-manual & 11.8 & 16.3 & 8.1 & 12.5 \\
Lower non-manual & 15.0 & 17.3 & 28.3 & 39.3 \\
Manual & 48.9 & 45.2 & 40.5 & 31.0 \\
Others & 24.3 & 21.3 & 23.2 & 17.2 \\
All & 100 & 100 & 100 & 100 \\
\hline Person years (in 1,000) & 1005 & 1374 & 1226 & 1545 \\
\hline
\end{tabular}


Three occupational social classes were distinguished: upper non-manual workers, lower non-manual workers and manual workers. Economically active persons were classified according to the occupation reported in the census at the beginning of each five-year period. Pensioners, unemployed persons and those for whom no occupational information was available were classified according to occupational information from earlier censuses. Housewives and other family members working at home were classified according to head of household's occupation. In the analysis by occupational class farmers, self-employed, and entrepreneurs were excluded in order to have a hierarchical variable comparable to level of education. The percentage of men excluded was 24.3 percent in 1981 and 21.3 in 2000, and the percentage of women 23.2 and 17.2, respectively. The changes in the occupational class distribution were smaller than those in the educational distribution particularly among men (Table 1).

The information on causes of death was based on various Finnish revisions of the International Classification of Diseases and Causes of Death (ICD) and harmonized by Statistics Finland to provide comparability over time. We used ten causes (or groups of causes) of death for men and eleven for women (see Table 4). Findings from earlier Finnish studies on differential mortality were utilized in the construction of the categories of causes of death.

Annual life expectancies at age 35 by sex were calculated by level of education and by occupational class by the standard method for the construction of abridged life tables (Shryock and Siegel 1976). Life expectancies were also calculated for the periods 1981-83, 1989-1991 and 1998-2000. The changes in life expectancy between educational categories and occupational classes from 1989-91 to 1988-2000 were decomposed into age and cause of death specific contributions using the method for decomposing the difference between two life expectancies presented by the United Nations Secretariat (1988).

\section{Results}

\section{Trends in life expectancy}

Figures 1 and 2 show the trends in life expectancy by level of education and occupational class from 1981 to 2000. Two-year moving averages were used to diminish the effects of random variation. The patterns of changes in life expectancies by level of education and by occupational class are very similar. One relatively clear exception is the difference in the trends among women with tertiary education and female upper non-manual workers at the beginning of the 1980s: the life expectancy of women with tertiary education diminished slightly from 1981-82 to 1985-86 whereas that of upper manual workers increased during the same period. 
The life expectancy of men with tertiary education increased by 4.3 years from 1981-83 to 1998-2000, somewhat more than that of male upper non-manual workers (table 2). In both groups the increase was almost linear. In the bottom socioeconomic categories the increases were smaller than in the top categories, 2.5 years among men with basic education and 2.7 among manual workers (Table 2). As a consequence the difference between men with secondary and basic education increased by 1.8 years and that between upper non-manual and manual workers by 1.3 years. For both socioeconomic indicators approximately two thirds of the increase took place during the 1980s. In the 1980s the increase in life expectancy in the lower socioeconomic categories was smaller than in the 1990s.

The life expectancies in the middle categories (men with secondary education and lower non-manual workers and) were approximately half-way between the respective

Figure 1. Trends in life expectancy at age 35 by level of education 1981-2000, men and women (two-year moving averages).

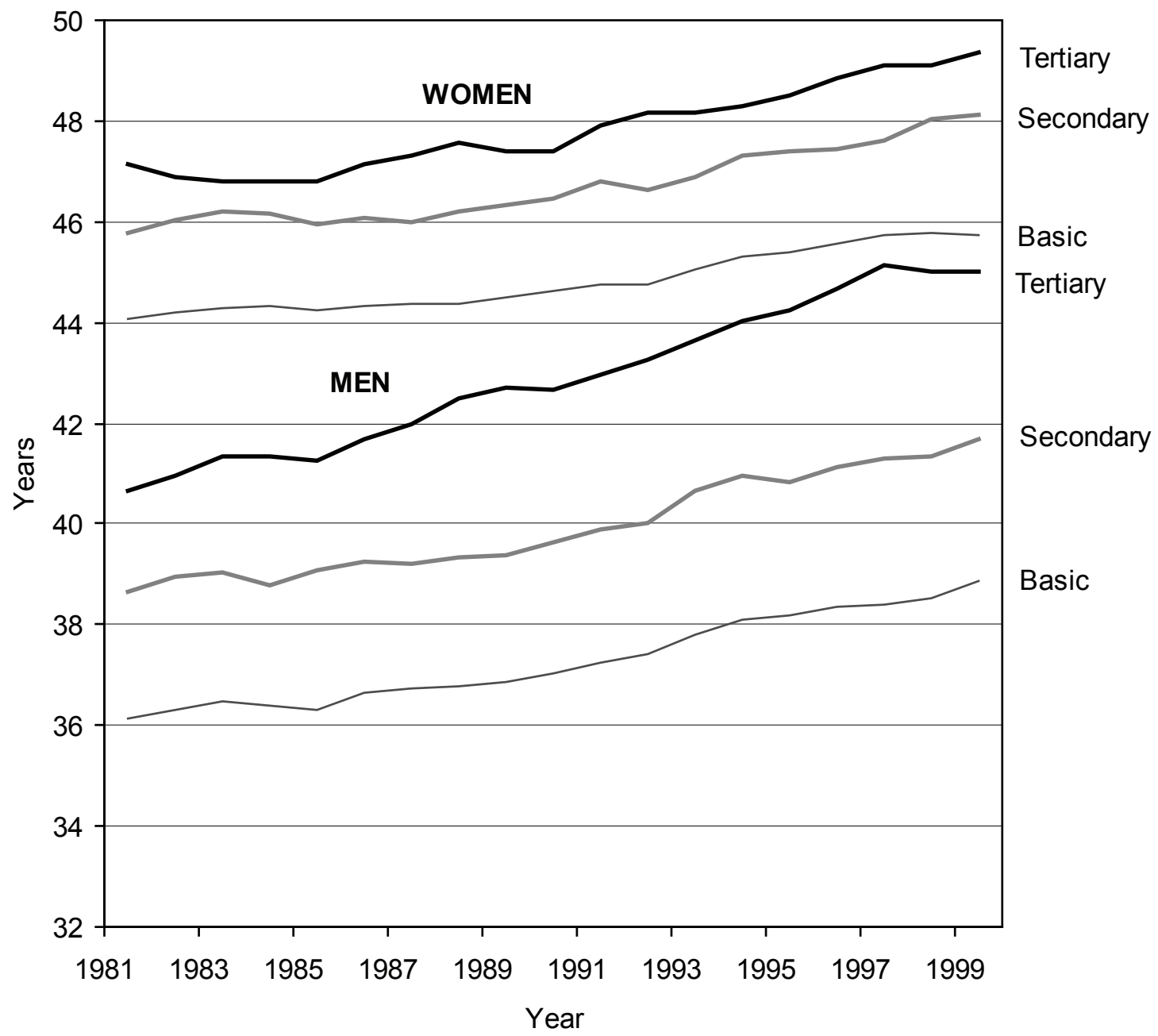


Figure 2. Trends in life expectancy at age 35 by occupational class 1981-2000, men and women (two-year moving averages).

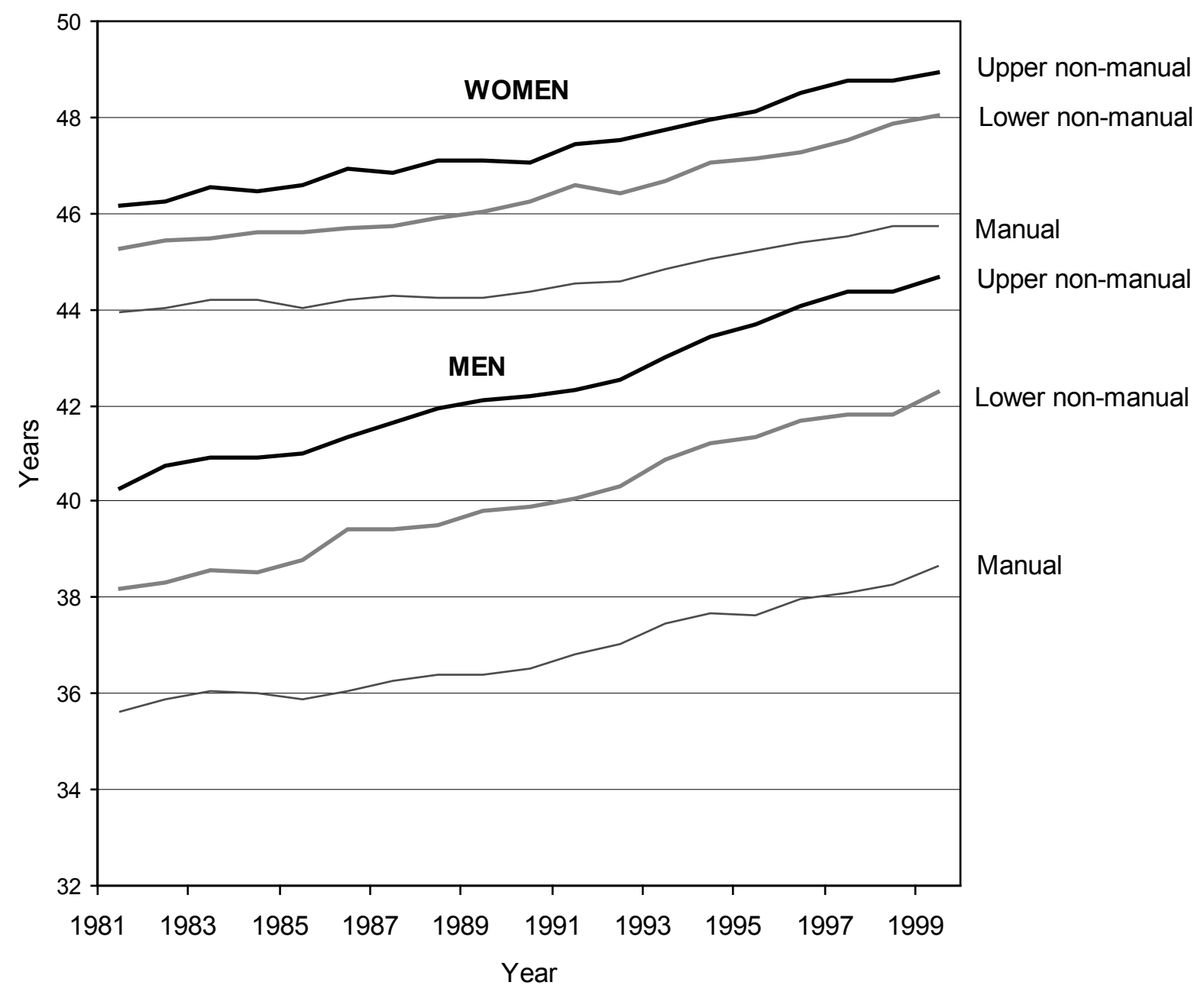

top and bottom categories at the beginning of the $1980 \mathrm{~s}$, but the trends were different after that. The life expectancy of lower non-manual workers increased almost as much that of upper non-manual workers, whereas life expectancy of men with secondary education increased 1.0 years less than that of men with tertiary education.

The increase in female life expectancy from 1981-83 to 1988-2000 was smaller than that of male life expectancy (Table 2). This was also the case in all socioeconomic categories. The difference between women with tertiary and basic education increased only slightly in the 1980s, while the difference between female upper non-manual and manual workers increased by one year. On the other hand, the increase in the educational gap in the 1990s was larger than the increase in the occupational class gap. The gap between the tertiary and basic educational categories increased by 0.6 years during the whole period 1981-3 to 1988-2000 and almost all of this increase took place during the 1990s. The difference in the life expectancy between female upper 
Table 2. Life expectancy (years) at age 35 by level of education and by occupational class, men and women in 1981-82, 1989-91 and 19982000.

\begin{tabular}{|c|c|c|c|c|c|c|}
\hline \multicolumn{7}{|c|}{ MEN } \\
\hline \multirow[b]{2}{*}{ Level of education } & \multirow[b]{2}{*}{$1981-83$} & \multirow[b]{2}{*}{$1989-91$} & \multirow[b]{2}{*}{ 1998-2000 } & \multicolumn{3}{|c|}{ Change } \\
\hline & & & & $\begin{array}{l}1981-83 \text { to } \\
1989-1991\end{array}$ & $\begin{array}{l}1989-91 \text { to } \\
1998-2000\end{array}$ & $\begin{array}{l}1981-83 \text { to } \\
1998-2000\end{array}$ \\
\hline Basic & 36.19 & 36.98 & 38.71 & 0.79 & 1.73 & 2.52 \\
\hline Secondary & 38.84 & 39.55 & 41.54 & 0.71 & 1.99 & 2.70 \\
\hline Tertiary & 40.82 & 42.75 & 45.13 & 1.93 & 2.39 & 4.32 \\
\hline All & 36.98 & 38.14 & 40.38 & 1.17 & 2.24 & 3.40 \\
\hline \multirow[t]{2}{*}{ Difference tertiary - basic } & 4.63 & 5.77 & 6.43 & 1.14 & 0.66 & 1.80 \\
\hline & & & & \multicolumn{3}{|c|}{ Change } \\
\hline Occupational class & $1981-83$ & 1989-91 & 1998-2000 & $\begin{array}{l}1981-83 \text { to } \\
1989-1991\end{array}$ & $\begin{array}{l}1989-91 \text { to } \\
1998-2000\end{array}$ & $\begin{array}{l}1981-83 \text { to } \\
1998-2000\end{array}$ \\
\hline Upper non-manual & 40.50 & 42.20 & 44.57 & 1.70 & 2.37 & 4.07 \\
\hline Lower non-manual & 38.28 & 39.86 & 42.11 & 1.58 & 2.25 & 3.83 \\
\hline Manual & 35.72 & 36.51 & 38.46 & 0.79 & 1.95 & 2.74 \\
\hline All* & 36.98 & 38.14 & 40.38 & 1.17 & 2.24 & 3.40 \\
\hline $\begin{array}{l}\text { Difference upper non- } \\
\text { manual - manual }\end{array}$ & 4.78 & 5.69 & 6.11 & 0.91 & 0.42 & 1.33 \\
\hline \multicolumn{7}{|c|}{ WOMEN } \\
\hline \multirow[b]{2}{*}{ Level of education } & \multirow[b]{2}{*}{ 1981-83 } & \multirow[b]{2}{*}{ 1989-91 } & \multirow[b]{2}{*}{ 1998-2000 } & \multicolumn{3}{|c|}{ Change } \\
\hline & & & & $\begin{array}{l}1981-83 \text { to } \\
1989-1991 \\
\end{array}$ & $\begin{array}{l}1989-91 \text { to } \\
1998-2000 \\
\end{array}$ & $\begin{array}{l}1981-83 \text { to } \\
1998-2000 \\
\end{array}$ \\
\hline Basic & 44.07 & 44.56 & 45.78 & 0.49 & 1.21 & 1.70 \\
\hline Secondary & 45.84 & 46.49 & 48.02 & 0.65 & 1.53 & 2.18 \\
\hline Tertiary & 46.98 & 47.49 & 49.26 & 0.51 & 1.77 & 2.28 \\
\hline All & 44.42 & 45.12 & 46.83 & 0.69 & 1.71 & 2.41 \\
\hline \multirow[t]{2}{*}{ Difference tertiary - basic } & 2.90 & 2.92 & 3.49 & 0.02 & 0.56 & 0.58 \\
\hline & & & & \multicolumn{3}{|c|}{ Change } \\
\hline Occupational class & $1981-83$ & 1989-91 & 1998-2000 & $\begin{array}{l}1981-83 \text { to } \\
1989-1991\end{array}$ & $\begin{array}{l}1989-91 \text { to } \\
1998-2000\end{array}$ & $\begin{array}{l}1981-83 \text { to } \\
1998-2000\end{array}$ \\
\hline Upper non-manual & 46.24 & 47.18 & 48.89 & 0.94 & 1.71 & 2.65 \\
\hline Lower non-manual & 45.26 & 46.17 & 47.93 & 0.91 & 1.76 & 2.67 \\
\hline Manual & 43.96 & 44.33 & 45.73 & 0.36 & 1.40 & 1.77 \\
\hline All* & 44.42 & 45.12 & 46.83 & 0.69 & 1.72 & 2.41 \\
\hline $\begin{array}{l}\text { Difference upper non- } \\
\text { manual - manual }\end{array}$ & 2.27 & 2.85 & 3.16 & 0.58 & 0.30 & 0.88 \\
\hline
\end{tabular}

*) Including farmers, self-employed, entrepreneurs and others. 
non-manual and manual workers increased by 0.9 years. As among men two thirds if this increase took place in the 1980s.

\section{Contributions of changes in age-specific death rates to changes in the life expectancy gap between the top and bottom socioeco- nomic categories}

The decomposition analysis of the changes in life expectancy concentrates on the period from 1989-91 to 1998-2000. The upper part of Table 3 shows for the tertiary and basic educational categories, how many years the change in mortality in each ten-year age group has contributed to the change in life expectancy. A positive contribution in an age group means that the death rates has decreased, whereas as a negative contribution results from an increase in the death rate. The sum of the age-specific contributions in a given educational category equals to the total change in life the expectancy. The differences between tertiary and basic education categories indicate the contribution of each age group to the total increase in the life expectancy gap, which was 0.66 years among men and 0.56 years among women.

There is a clear difference in the patterns of age-specific contributions between men and women. Among men all age-groups except the oldest one contributed markedly to the total increase in life expectancy within each education group. The decrease in death rates in the ages 55 to 74 contributed 60 percent of the total increase. Among women more than 90 percent of the increase was due to the age groups above the age of 65 , whereas the contribution of the ages from 35 to 64 was less than 10 percent.

The contributions of the changes in the death rates by age to the increase in the tertiary-basic life expectancy gap (column 'differences' in Table 3) do not show a regular pattern for either men or women. Among men all age groups contributed to the increase in the gap, the largest contributions coming from larger decrease in death rates in the tertiary education category in age groups $45-49$ and 75-84. Among women with basic education mortality increased in ages 35-54 whereas there was no change or a slight decrease in the mortality among women with tertiary education. These youngest age groups accounted for almost 60 per cent of the total increase in the female life expectancy gap. In the age group 75-84 a larger decrease in mortality among women with basic education slowed down the increase in the gap.

The lower part of Table 3 is similar to the upper part, but shows the contributions of age-specific death rates to the changes in life expectancy by occupational class. As shown earlier the life expectancy gap between occupational classes increased less than that between educational categories among both men and women. Taking this into account the main patterns of the age-specific contributions to the increase in the 
Table 3. Contributions (years) of changes in age-specific death rates to changes in life expectancy at age 35 from 1989-91 to 1998-2000 in the top and bottom educational categories and occupational classes, men and women.

\begin{tabular}{|c|c|c|c|c|c|c|c|c|}
\hline \multirow[b]{3}{*}{ Age } & \multicolumn{4}{|c|}{ MEN } & \multicolumn{4}{|c|}{ WOMEN } \\
\hline & \multicolumn{2}{|c|}{ Level of education } & \multirow{2}{*}{ Difference } & \multirow{2}{*}{ All men } & \multicolumn{2}{|c|}{ Level of education } & \multirow{2}{*}{ Difference } & \multirow{2}{*}{$\begin{array}{c}\text { All } \\
\text { women }\end{array}$} \\
\hline & Tertiary & Basic & & & Tertiary & Basic & & \\
\hline $35-44$ & 0.18 & 0.14 & 0.04 & 0.27 & 0.00 & -0.13 & 0.12 & 0.08 \\
\hline $45-54$ & 0.32 & 0.14 & 0.18 & 0.24 & 0.16 & -0.07 & 0.23 & 0.07 \\
\hline $55-64$ & 0.67 & 0.56 & 0.11 & 0.68 & 0.27 & 0.16 & 0.11 & 0.23 \\
\hline $65-74$ & 0.70 & 0.58 & 0.11 & 0.68 & 0.69 & 0.55 & 0.14 & 0.60 \\
\hline $75-84$ & 0.47 & 0.27 & 0.20 & 0.32 & 0.44 & 0.58 & -0.13 & 0.60 \\
\hline $85-$ & 0.05 & 0.04 & 0.02 & 0.04 & 0.22 & 0.12 & 0.10 & 0.13 \\
\hline \multirow[t]{2}{*}{ All } & 2.39 & 1.73 & 0.66 & 2.24 & 1.77 & 1.21 & 0.56 & 1.71 \\
\hline & \multicolumn{4}{|c|}{ MEN } & \multicolumn{4}{|c|}{ WOMEN } \\
\hline \multirow[b]{2}{*}{ Age } & \multicolumn{2}{|c|}{ Occupational class } & \multirow[b]{2}{*}{ Difference } & \multirow[b]{2}{*}{ All men* } & \multicolumn{2}{|c|}{ Occupational class } & & \\
\hline & $\begin{array}{c}\text { Upper } \\
\text { non- } \\
\text { manual }\end{array}$ & Manual & & & $\begin{array}{c}\text { Upper } \\
\text { non- } \\
\text { manual }\end{array}$ & Manual & Difference & $\begin{array}{c}\text { All } \\
\text { women* }\end{array}$ \\
\hline $35-44$ & 0.13 & 0.27 & -0.14 & 0.27 & 0.03 & 0.10 & -0.07 & 0.08 \\
\hline $45-54$ & 0.35 & 0.17 & 0.18 & 0.24 & 0.14 & -0.06 & 0.20 & 0.07 \\
\hline $55-64$ & 0.63 & 0.57 & 0.06 & 0.68 & 0.17 & 0.18 & -0.01 & 0.23 \\
\hline $65-74$ & 0.74 & 0.60 & 0.14 & 0.68 & 0.60 & 0.49 & 0.11 & 0.60 \\
\hline $75-84$ & 0.43 & 0.32 & 0.12 & 0.32 & 0.60 & 0.57 & 0.03 & 0.60 \\
\hline $85-$ & 0.09 & 0.03 & 0.06 & 0.04 & 0.16 & 0.12 & 0.04 & 0.13 \\
\hline All & 2.37 & 1.95 & 0.42 & 2.24 & 1.71 & 1.40 & 0.30 & 1.71 \\
\hline
\end{tabular}

*) Including farmers, self-employed, entrepreneurs and others.

life expectancy gap by occupational class are relatively similar to those by level of education.

\section{Contributions of changes in cause specific death rates to the increase in the life expectancy gap between the top and bottom socioeconomic categories}

Table 4 is similar to Table 3 , but shows the contributions of changes in cause-specific death rates instead of age-specific death rates to the changes in life expectancies in the top and bottom categories of level of education and occupational class. The large decrease in mortality from ischemic heart disease accounted for more than half of the total increase in life expectancy among all men (Table 4, last column). The decrease 
Table 4. Contributions (years) of changes in mortality from selected causes of death to changes in life expectancy at age 35 from 1989-91 to 1998-2000 in the top and bottom educational categories and occupational classes, men and women.

\begin{tabular}{|c|c|c|c|c|c|c|c|c|}
\hline \multirow[b]{3}{*}{ Cause of death } & \multicolumn{4}{|c|}{ MEN } & \multicolumn{4}{|c|}{ WOMEN } \\
\hline & \multicolumn{2}{|c|}{ Level of education } & \multirow{2}{*}{ Difference } & \multirow{2}{*}{$\begin{array}{c}\text { All } \\
\text { men }\end{array}$} & \multicolumn{2}{|c|}{ Level of education } & \multirow{2}{*}{ - Difference } & \multirow{2}{*}{$\begin{array}{c}\text { All } \\
\text { women }\end{array}$} \\
\hline & Tertiary & Basic & & & Tertiary & Basic & & \\
\hline Lung cancer & 0.07 & 0.19 & -0.12 & 0.21 & -0.03 & -0.03 & -0.01 & -0.02 \\
\hline Breast cancer & & & & & 0.03 & 0.00 & 0.03 & 0.01 \\
\hline Other cancers & 0.27 & 0.10 & 0.17 & 0.15 & 0.27 & 0.12 & 0.15 & 0.23 \\
\hline Ischemic heart disease & 1.04 & 1.07 & -0.03 & 1.17 & 0.63 & 0.62 & 0.01 & 0.66 \\
\hline $\begin{array}{l}\text { Cerebrovascular } \\
\text { disease }\end{array}$ & 0.32 & 0.21 & 0.11 & 0.23 & 0.26 & 0.34 & -0.07 & 0.36 \\
\hline $\begin{array}{l}\text { Other circulatory } \\
\text { diseases }\end{array}$ & 0.19 & 0.19 & 0.00 & 0.22 & 0.22 & 0.29 & -0.07 & 0.32 \\
\hline Respiratory diseases & 0.18 & 0.03 & 0.14 & 0.07 & 0.10 & -0.02 & 0.12 & 0.03 \\
\hline Alcohol-related diseases & 0.02 & -0.21 & 0.23 & -0.10 & -0.03 & -0.15 & 0.12 & -0.06 \\
\hline Other diseases & 0.00 & -0.05 & 0.05 & 0.02 & 0.26 & -0.04 & 0.29 & 0.07 \\
\hline Suicide & 0.13 & 0.08 & 0.05 & 0.12 & 0.03 & 0.04 & 0.00 & 0.04 \\
\hline Accidents and violence & 0.17 & 0.12 & 0.04 & 0.16 & 0.04 & 0.04 & 0.00 & 0.08 \\
\hline All & 2.39 & 1.73 & 0.66 & 2.24 & 1.77 & 1.21 & 0.56 & 1.71 \\
\hline & \multicolumn{2}{|c|}{ Occupational class } & & & \multicolumn{2}{|c|}{ Occupational class } & & \\
\hline Cause of death & $\begin{array}{l}\text { Upper } \\
\text { non- } \\
\text { manual }\end{array}$ & Manual & Difference & $\begin{array}{c}\text { All } \\
\text { men* }\end{array}$ & $\begin{array}{c}\text { Upper } \\
\text { non- } \\
\text { manual }\end{array}$ & Manual & Difference & $\begin{array}{c}\text { All } \\
\text { women* }\end{array}$ \\
\hline Lung cancer & 0.11 & 0.23 & -0.13 & 0.21 & -0.03 & -0.03 & 0.00 & -0.02 \\
\hline Breast cancer & & & & & 0.00 & 0.01 & 0.00 & 0.01 \\
\hline Other cancers & 0.27 & 0.10 & 0.17 & 0.15 & 0.38 & 0.21 & 0.17 & 0.23 \\
\hline Ischemic heart disease & 1.08 & 1.05 & 0.02 & 1.17 & 0.70 & 0.58 & 0.12 & 0.66 \\
\hline $\begin{array}{l}\text { Cerebrovascular } \\
\text { disease }\end{array}$ & 0.30 & 0.22 & 0.08 & 0.23 & 0.21 & 0.34 & -0.13 & 0.36 \\
\hline $\begin{array}{l}\text { Other circulatory } \\
\text { diseases }\end{array}$ & 0.23 & 0.22 & 0.01 & 0.22 & 0.15 & 0.29 & -0.14 & 0.32 \\
\hline Respiratory diseases & 0.09 & 0.07 & 0.02 & 0.07 & -0.01 & 0.01 & -0.02 & 0.03 \\
\hline Alcohol-related diseases & 0.02 & -0.18 & 0.20 & -0.10 & -0.03 & -0.15 & 0.11 & -0.06 \\
\hline Other diseases & 0.02 & -0.02 & 0.05 & 0.02 & 0.26 & 0.01 & 0.24 & 0.07 \\
\hline Suicide & 0.12 & 0.13 & -0.01 & 0.12 & 0.03 & 0.07 & -0.04 & 0.04 \\
\hline Accidents and violence & 0.12 & 0.13 & 0.00 & 0.16 & 0.05 & 0.06 & -0.01 & 0.08 \\
\hline All & 2.37 & 1.95 & 0.42 & 2.24 & 1.71 & 1.40 & 0.30 & 1.71 \\
\hline
\end{tabular}

*) Including farmers, self-employed, entrepreneurs and others. 
in mortality from most other causes of death also contributed to the increase in male life expectancy. After ischemic heart disease the next most important contributions were made by cerebrovascular diseases, other cardiovascular diseases, lung cancer and accidents and violence. Only mortality from alcohol-related causes of death (alcoholrelated diseases and alcohol poisoning) increased and slowed down the increase in life expectancy by 0.10 years.

More than a third of the increase in the difference in the life expectancy between men with tertiary and basic education was due to the increase in alcohol-related mortality among men with basic education together with the simultaneous decrease among men with tertiary education. Mortality from suicide, accidents and violence decreased among men in both educational categories, but more among men with tertiary education than basic education.

Mortality from other cancers than lung cancer diminished more among men with tertiary than basic education, which contributed 0.17 years to the increase in the life expectancy gap. On the other hand, a substantial decrease in lung cancer mortality benefited more men with basic education than men with tertiary education. However, lung cancer mortality was still three times higher among men with basic than tertiary education at the end of the 1990s.

The changes in mortality from ischemic heart disease did not contribute to the increase in the educational life expectancy gap in the 1990s. The decrease in mortality from ischemic heart disease led to an increase of 1.04 years in the life expectancy among men with tertiary education and an increase of 1.07 years among men with basic education. The decrease in mortality from cerebrovascular diseases benefited men with tertiary education somewhat more than men with basic education but other circulatory diseases had no effect on the life expectancy gap. Altogether changes in mortality from cardiovascular diseases made only a minor contribution ( 0.08 years) to the growth of the life expectancy gap from 1989-91 to 1998-2000.

The results from the cause of death decomposition of the changes in male life expectancy in the top and bottom occupational class were mainly similar to those for education. The numbers are somewhat different because the occupational class life expectancy gap increased less than the educational gap, but the general conclusions are the same: alcohol-related causes of death and cancers other than lung cancer made the largest contributions to the widening of the gap, whereas cardiovascular diseases were of small importance. The only clear difference concerns respiratory diseases, which made a larger contribution to the growth of the life expectancy gap by level of education than by occupational class. 
Female life expectancy at age 35 increased by 1.71 years during the period studied. The relative contribution of cardiovascular diseases was larger than among men and they accounted of almost 80 per cent of the total increase (Table 4 ). The contribution of the decline in ischemic heart disease mortality was smaller and the contribution of cerebrovascular and other cardiovascular diseases larger than among men.

The difference in the life expectancy between women with tertiary and basic education increased by 0.56 years. Approximately half of this increase was due to the slight increase in mortality from the heterogeneous 'other diseases' category among the basic educated and a rapid decline in mortality from the same causes among the tertiary educated. Another equally heterogeneous category 'other cancers' accounted for a fourth of the increase in the gap. Respiratory diseases and alcohol-related causes also contributed substantially to the increase in the life expectancy gap. The decline in mortality from ischemic heart disease benefited women with tertiary and basic education equally, but the decline in cerebrovascular and other circulatory diseases was faster among women with basic than tertiary education. The development of mortality from all cardiovascular diseases together contributed to the decrease in the mortality gap.

Lung cancer mortality increased slightly in both educational categories among women whereas suicide mortality and mortality from accident and violence diminished. Breast cancer mortality increased slightly among women with tertiary education but remained constant among women with basic education. In total lung cancer, breast cancer, suicide and accidents and violence had almost no influence on the change in the female educational mortality gap.

The gap in life expectancy between female upper non-manual and manual workers increased much less than that between women with tertiary and basic education $(0.30$ years vs. 0.56 years), because the decline of mortality from many diseases (particularly 'other cancers') contributed more to the increase in life expectancy for female manual workers than women with basic education. The general patterns of the contributions of causes of death were approximately the same for occupational social class as for level of education.

\section{Discussion}

One purpose of this study was to assess to what extent the trends if life expectancy by level of education and by occupational class are similar or different. The results show that the general patterns of trends by these two indicators were largely similar although there were differences in the quantities of changes and differences. One difference was observed in the patterns of change in the middle socioeconomic categories 
among men. The trend in life expectancy for lower non-manual workers was similar to the trend among upper non-manual workers, whereas the trend among men with secondary education was more similar to the trend among men with basic education. Among women the trends in both of these middle-categories were similar to those in the top category.

Another difference between the results for the two socioeconomic indicators was that there was no increase in the life expectancy of women with tertiary education in the 1980s. As a result there was little change in the gap between the life expectancy for women with tertiary and basic education during the 1980s whereas that between female upper non-manual and manual workers increased substantially. There is no obvious explanation for the difference. It may be linked to the difference in the composition of these groups. The occupational class of housewives was determined on the basis of the occupation of the husband, whereas the educational category was based on own education. The groups of women in the top occupational and educational categories may thus not overlap very well). The difference in the results by level education and occupational class may also be caused by the difference in the populations covered. The analysis by level education covers the whole population aged 35 and over, whereas that by occupational class does not cover farmers, other self-employed and entrepreneurs in this study and in most other studies. As both level of education and occupational class are commonly used in studies on socioeconomic differences in mortality and health, it would be useful to analyse the effects of the different coverage of data in more detail.

According to the targets presented in the Health 2015 Public health programme of the Government of Finland the difference in the life expectancy between persons with tertiary and basic education as well as that between upper-level manual workers and manual workers should have diminished after the first half of the 1990s. Our results show that the actual trends were contrary to these targets.

The difference between men with tertiary and basic education increased by 0.7 years and that between male upper non-manual and manual workers somewhat less, by 0.4 years from 1989-91 to 1998-2000. These increases were, however, only half of the increases that took place in the period from 1981-83 to 1989-91. This difference between the 1980s and 1990s was accounted for by difference in the trends in mortality from cardiovascular diseases. In the 1980s cardiovascular mortality decreased more in the non-manual than manual occupational class, which caused a major part of the increase in the life expectancy gap (Martikainen et al. 2001). In the 1990s the decrease in cardiovascular mortality contributed almost equally to the increase in male life expectancy in the top and bottom socioeconomic categories both according to level of education and occupational class. In other respects our results for men in the 1990s resemble those for the 1980s. Differences in the trends in mortality from 
alcohol-related causes of death and from other cancers than lung cancer accounted for most of the increase in the socioeconomic life expectancy gap in the 1990s. The decrease in lung cancer mortality contributed more to the increase in life expectancy among men with basic education and male manual workers than in the higher socioeconomic groups.

The absolute increase in the socioeconomic life expectancy gap was almost as large among women as men in the 1990s: 0.6 years by level of education and 0.3 years by occupational class. However, the relative increase was larger among women than among men, because the size of the difference among women at the beginning of the 1990s was only half of that among men. The increase in the difference in life expectancy between the upper non-manual and manual classes in the 1990s was half of that in the 1980s in the same way as among men. The increase in the female life expectancy gap was mainly due to mortality from the heterogeneous category of 'other diseases' and cancers other than lung and breast cancer. Compared to upper non-manual workers, manual workers benefited more from the decline in cardiovascular mortality in the 1990s than in the 1980s (Martikainen et al. 2001), which accounts for the smaller increase in the gap in the 1990s.

Changes in socioeconomic differences in life expectancy do not result only from 'real' differences in changes in death rates but also from changes in the distributions of population into the socioeconomic categories. According to the results the increase in the life expectancy gap was larger between the top and bottom categories of education than those of occupational class (with the exception of the stagnation in the life expectancy for women with tertiary education at the beginning of the 1980s). This may imply that over time education has become a more important determinant of mortality than occupational social class. Another possibility is that this is due to the larger changes in the distribution of education than occupational class. As Table 1 shows the share of persons with basic education diminished strongly. The share of manual workers diminished too, but not as much. The more rapid widening of the life expectancy gap by level of education could have been due to the increased selectivity of persons with basic education in terms of material living conditions, health related behaviour and other risk factors of mortality.

\section{Acknowledgments}

We are grateful to Statistics Finland for the permission (TK-53-1783-96) to use the data for this study. Pekka Martikainen has been supported by the Academy of Finland grant $(70631,48600,210752)$. 


\section{References}

Buström, Kristina, Magnus Johannesson and Finn Diderichsen. 2005. Increasing socio-economic inequalities in life expectancy and QALYs in Sweden 1980-1997. Health Economics 42:831-850.

Crimmins, Eileen M. and Yasuhiko Saito. 2001. Trends in healthy life expectancy in the United States, 1970-1990: gender, racial, and educational differences. Social Science \& Medicine 52(11):1,629-41.

Donkin, Angela, Peter Goldblatt and Kevin Lynch. 2002. Inequalities in life expectancy by social class, 1972-1999. Health Statistics Quarterly 15:5-15.

Government resolution on the Health 2015 public health programme. 2001. Publications of the Ministry of Social Affairs and Health 2001:6.

Hattersley, Lin. 1999. Trends in life expectancy by social class - an update. Health Statistics Quartely 2:16-24.

Kunst, Anton E., Vivian Bos, Otto Andersen, Mario Cardano, Giuseppe Costa, Seeromanie Harding, Örjan Hemström, Richard Layte, Enrique Regidor, Alison Reid, Paula Santana, Tapani Valkonen and Johan P. Mackenbach. 2004. Monitoring of trends in socioeconomic inequalities in mortality: Experiences from a European project. Demographic Research 16 April; Special Collection 2, Article 9:229-53.

Leinsalu, Mall, Denny Vågerö and Anton E. Kunst. 2003. Estonia 1989-2000: enormous increase in mortality differences by education. International Journal of Epidemiology 32(6):1,081-7.

Mackenbach, Johan and Martinje Bakker (eds). 2002. Reducing inequalities in health. A European perspective. London: Routledge.

Mackenbach, Johan P., Vivian Bos, Otto Andersen, Mario Cardano, Giuseppe Costa, Seeromanie Harding, Alison Reid, Örjan Hemström, Tapani Valkonen and Anton E. Kunst. 2003. Widening socioeconomic inequalities in mortality in six Western European countries. International Journal of Epidemiology 32(5):830-7.

Martikainen, Pekka, Tuija Martelin and Tapani Valkonen. 2001. Change in male and female life expectancy by social class: decomposition by age and cause of death in Finland 1971-95. Journal of Epidemiology and Community Health 55(7):494-9.

Martikainen, Pekka and Tapani Valkonen. 1995. Lama ja ennenaikainen kuolleisuus (Recession and premature mortality). SVT Väestö 1995:11. Helsinki: Tilastokeskus.

Rognerud, Marit A. and Per-Henrik Zahl. 2006. Social inequalities in mortality: changes in the relative importance of income, education and household size over a 27 -year period. European Journal of Public Health 16(1):62-8.

Shryock, Henry S. and Jacob S. Siegel. 1976. The methods and materials of demography. New York: Academic Press.

United Nations Secretariat. 1988. Sex differentials in life expectancy and mortality in developed countries: an analysis by age groups and causes of death from recent and historical data. Population Bulletin of the United Nations 25:65-107.

Valkonen, Tapani. 1999. The widening differentials in adult mortality by socio-economic status and their causes. In: Health and mortality: Issues of Global Concern, Brussels, 19-22 November 1997, edited by Joseph Chamie and Robert L. Cliquet, pp. 291-312. Leuven: Population Division, Department of Economic and Social Affairs, United Nations Secretariat and Population and Family Study Centre, Flemish Institute. 
Valkonen, Tapani, Hilkka Ahonen and Pekka Martikainen. 2003. Sosiaaliryhmien väliset erot elinajanodotteessa kasvoivat 1990-luvun loppuvuosina (Differences in life expectancy between occupational classes increased during the second half of the 1990s). Hyvinvointikatsaus 2/2003:12-18.

Valkonen, Tapani, Tuija Martelin, Arja Rimpelä, Veijo Notkola and Soili Savela. 1993. Socioeconomic mortality differences in Finland 1981-90. Population 1993, No. 1. Helsinki: Statistics Finland.

Valkonen, Tapani, Pekka Martikainen, Marika Jalovaara, Seppo Koskinen, Tuija Martelin and Pia Mäkelä. 2000. Changes in socioeconomic inequalities in male mortality during economic boom and recession in Finland. European Journal of Public Health 10:274-80.

World Health Organization. 1999. Health 21 - Health for all in the 21 st century. Copenhagen: World Health Organization.

World Health Organization. 1985. Targets for health for all. Targets in support for the European strategy for health for all. Copenhagen: World Health Organization, Regional Office for Europe. 